\title{
RADAR Remote Sensing Combined with Continuous GPS Measurements for the Monitoring of Deformations of Geothermal Fields: A Proposed Methodology
}

\author{
J N Mbogo, J N Kebu* \\ Kenya Electricity Generating Company Ltd., Kenya
}

Copyright $(2017$ by authors, all rights reserved. Authors agree that this article remains permanently open access under the terms of the Creative Commons Attribution License 4.0 International License

\begin{abstract}
Electricity generation from geothermal sources is associated with geothermal fluid extraction and re-injection, resulting in surface changes/displacements horizontally and vertically (uplift or sinking) (Eneva, 2009). Besides, previous geodetic monitoring of geothermal production sites have shown large subsidence and horizontal displacement at tribute to thermal contraction, pressure reduction in the reservoir, and/or changes in the local stress field (Heimlich, Masson, \& Gourmelen, 2013). Conventional surveying methods employed to measure the deformations of structures with small and slow displacements have often provided in frequent though precise estimates of these deformations. With the development of high precision GPS methods and Remote Sensing, an alternative method for monitoring structural deformations is available. Continuous GPS measurements technique with its higher temporal resolution is complemented with RADAR remote sensing so as to cover larger areas spatially. Citing case studies, this paper fronts the application of RADAR Remote Sensing complimented with continuous GPS measurements as an ideal way of monitoring deformations of geothermal fields for better geothermal field management. A similar proposition has been forwarded for approval in the management of Olkaria Geothermal Field which houses the largest geothermal power plant in Africa.
\end{abstract}

Keywords RADAR Remote Sensing, Geothermal Sources, Deformation Monitoring

\section{Introduction}

\subsection{Background}

Deformation monitoring also referred to as Deformation survey is the systematic measurement and tracking of the alteration in the shape or dimensions of an object as a result of stresses induced by applied loads. Engineering structures (such as dams, bridges, viaducts, high rise buildings, etc.) are subject to deformations as well as geophysical phenomena. This could be due to factors such as changes of ground water level, tidal phenomena, tectonic phenomena etc.

Remote sensing is the science (and to some extent, art) of acquiring information about the Earth's surface without actually being in contact with it. This is done by sensing and recording reflected or emitted energy and processing, analyzing, and applying that information. This process involves an interaction between incident radiation and the targets of interest. There are many types of remote sensing techniques depending on the portion of the electromagnetic spectrum that they are carried out. Microwave remote sensing is an example that utilizes the microwave portion of the spectrum with wavelengths between one centimeter and one metre (Canadian Centre for Remote Sensing). Longer wavelength of microwave radiation can penetrate through cloud cover, haze, dust, and are not susceptible to atmospheric scattering which affects shorter optical wavelengths. RADAR is the most common form of imaging active remote sensing microwave sensors. RADAR is an acronym for Radio Detection and Ranging, which essentially characterizes the function and operation of a radar sensor. The sensor transmits a microwave (radio) signal towards the target and detects the back scattered portion of the signal.

Satellite interferometric synthetic aperture radar techniques have been used for quite some time to detect surface deformations. Remote sensing that employs Radar Satellites constantly shoot beams of radar waves towards Earth that is documented after bouncing off Earth's surface. As these waves bounce off Earth they provide information that can be used to obtain elevation or surface change. The surface deformation detected by any interferometric synthetic aperture radar technique is first measured in the 
line of sight to the satellite. Therefore, knowledge of the satellite orbit geometry and especially when data from both the ascending and descending orbits are available make it possible to infer both horizontal and vertical components of the surface displacements (Eneva, 2009).

Electricity generation from geothermal sources is associated with geothermal fluid extraction and re-injection, this can and do result in surface changes/displacements horizontally and vertically (uplift or sinking)(Eneva, 2009). Besides, previous geodetic monitoring of geothermal production sites have shown large subsidence and horizontal

displacementattributedtothermalcontraction,pressurereducti oninthereservoir,and/orchangesinthelocalstressfield(Heimlic h, Masson, \& Gourmelen, 2013 ).With the increased geothermal fluid extraction in the Olkaria Geothermal field owing to electricity generation, it is compelling to devise precise and cost effective tools to monitor these changes beyond ground based leveling techniques that only capture vertical movements.

With recent advances in InSAR to the use of permanent/persistent scatters has made it possible to use time series of synthetic aperture radar scenes to extract time series of surface deformations at the locations of permanent/persistent scatters. Permanent scatters here refer to manmade structures or rocks that can be identified amidst vegetation. Deformation velocities also termed deformation rates can then be calculated from these observations. Permanent scatter interferometry has been established to achieve precisions of less than $0.1 \mathrm{~mm} /$ year (Eneva, 2009).

\subsection{Status of Deformation Monitoring at Olkaria Geothermal Project}

Olkaria Geothermal Project poses as the largest installation generating electricity from geothermal resources in Africa. There are currently five power stations in Olkaria with Olkaria I, Olkaria II Olkaria IAU and Olkaria IV owned and operated by KenGen Ltd and Olkaria III owned and operated by Or Power Inc. These installations combined with feeder infrastructure like, well head electric power generators, high voltage transmission lines, steam reticulation and wells are mega engineering structures that constantly need to be monitored for deformations. Besides, the geothermal reservoir beneath is also actively changing owing to fluid extraction and re-injection and magmatic movement.

At present, there is no established deformation monitoring network but there are efforts by the Geomatics section to establish survey monuments as a pre requisite for deformation monitoring. The present approach of using conventional methods (precise leveling for vertical movements and theodolite surveys for horizontal movements), is quite slow and yet at present signs of deformations have been note date specially Olkaria II power station.

\subsection{Objective}

This proposed study endeavours to use PS-InSAR complimented by continuous observations to establish a deformation monitoring network and thus determine the ground deformations/owing to electricity generation from the geothermal resources of the Olkaria Geothermal Field.

\subsection{Case Studies}

1.4.1. Geodetic Monitoring at the Geothermal Sites of Soultz-Sous-Forêts and Rittershoffen (Upper Rhine Graben - France)

This study employed GNSS and InSAR methods are complementary approaches to produce high precision (in millimeter to sub-millimetres order) of the surface displacement. Ten year SAR data (1991-2011) was obtained from ERS-2 and ERS-2 satellites complimented with GNSS data from one permanent station and three other sites (Heimlich, Masson, \& Gourmelen, 2013 ).

\subsubsection{Continuation of Survey GPS Measurements and Installation of Continuous GPS Sites at the Geysers, California}

This study employed systematicle velling data from GPS surveys from the years 1994-1996, 2009-2011. Permanent Scatter interferometric synthetic aperture radar (PS-InSAR) measurements from the same period as the 1990s GPS data were also incorporated and aligned to the same reference frame as the GPS data. The results indicated a slowing of the rapid rate of subsidence and contraction seen across The Geysers (Floyd \& Funning).

\subsubsection{Deformation and Seismicity in the Coso Geothermal Area, Inyo County, California}

This study employed the use of Interferometric synthetic aperture radar (InSAR) data collected in the Coso geothermal area, eastern California, during the years 1993-1999. The results indicated ground subsidence over a $\sim 50 \mathrm{~km}^{2}$ region that approximately coincides with the production area of the Coso geothermal plant (Fialko \& Simons, 2000).

\section{Proposed Methodology}

\subsection{PS-InSAR}

For the purposes of this study Persistent Scatter Interferometry (PS-InSAR), which enables the detection of earth surface deformation at the millimeter level, shall be employed. The flow chart below describes the methodology that shall be employed in the proposed study for deformations estimation by PS-InSAR technique. 


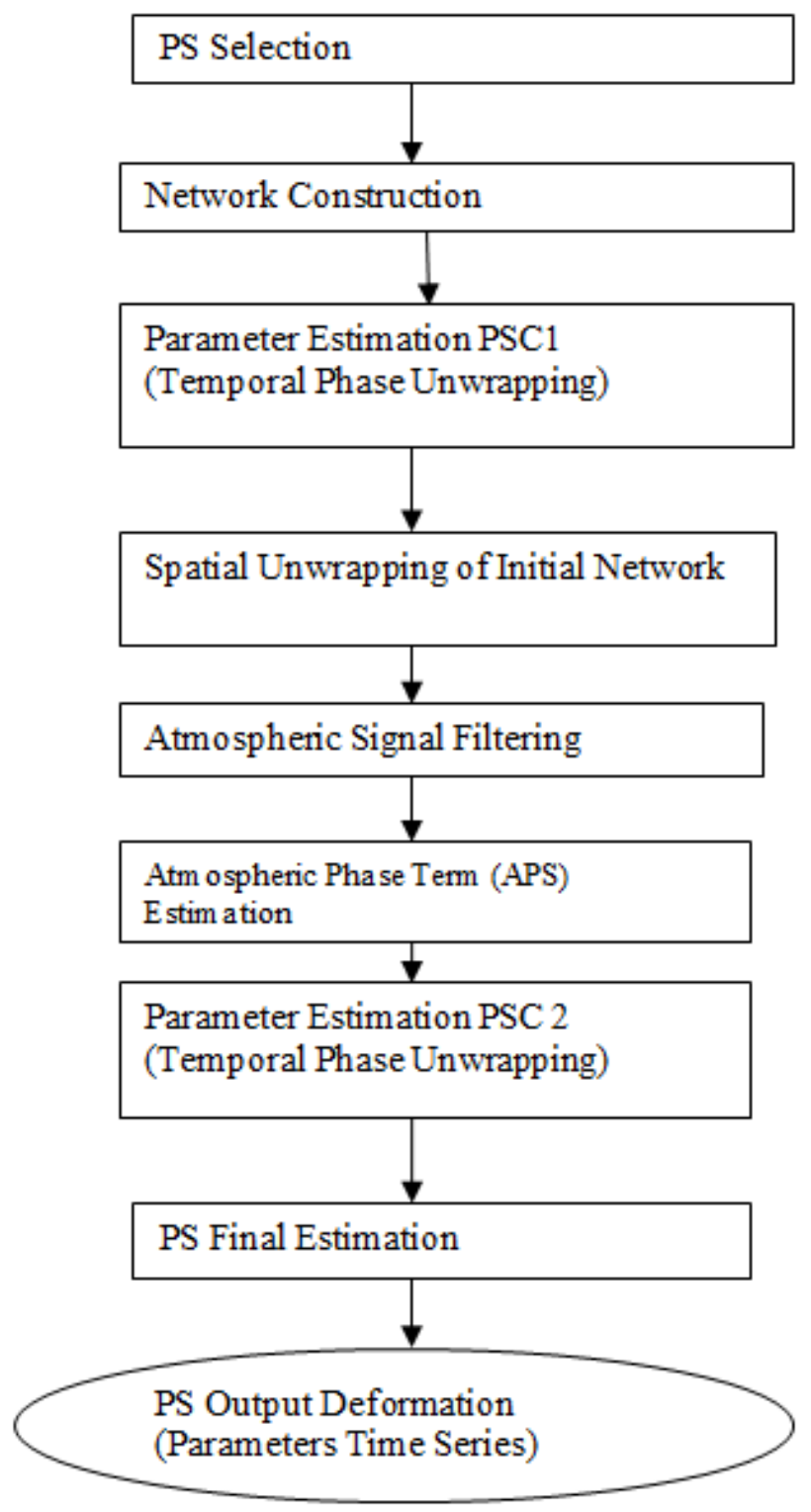

\subsection{Continuous Global Navigation Satellite System (GNSS)}

Due to the uncertainties in the SAR satellite orbit and the signal disturbances in the atmosphere, GPS surveys can be used to account for these biases (Ge, Rizos, Han, \& Zebker, 2001). Continuously-operated GPS receiver networks have been established in many parts of the world to address a variety of geodetic and survey applications, on arrange of spatial scales such as measuring ground subsidence over small areal extents (due to underground mining, extraction of fluids, etc.), tracking surface crustal deformation on local and regional scales associated with active seismic faults and volcanoes, and local monitoring of slope stability (Ge, Rizos, Han, \& Zebker, 2001).

This study proposes creation of three continuous GNSS stations to enable continuous observations at the power plants and a dense GNSS network to enable continuous data close to the wells and power plants. GPS measurements shall be made bi-annually. The session length is 1 hour and the sampling interval is 10 seconds. At each observation point, the session shall be repeated 10 to 20 times and data processed using relevant software.

\subsection{Expected Outcome}

GNSS and InSAR methods are complementary approaches to produce high precision (in millimeter to submillimeter order) of the surface displacements/deformations. This proposed study expects to yield surface displacement maps over the Olkaria Geothermal field with different colours showing the different deformation rates per year (Fialko \& Simons, 2000). Thesurfacedisplacementmapsarealsoexpectedtogivein formationonthereservoirbehaviourduringthesetimes. 
Since interferometric phase comparison of SAR images gathered at different times and with different base lines and has the potential to provide Digital Elevation Models (DEMs) with metre accuracy (Ferretti, Prati, \& Rocca, 2001), the proposed study is also expected to yield a Digital Elevation Model for the Olkaria Geothermal Field.

\section{REFERENCES}

[1] Canadian Centre for Remote Sensing. Fundamentals of Remote Sensing. Natural Resources Canada.

[2] Eneva M 2009 Application of InSAR to the Detection of Surface Deformation in the Geothermal Fields of Imperial Valley, California. Callifornia: California Energy Commission PIER Program. CEC - 500 - 2010 - 019

[3] Ferretti A, Prati C and Rocca F 2001 Permanent Scatterers in SAR Interferometry. IEEE transactions on geoscience and remote sensing VOL. 39, NO. 1

[4] Fialko Y and Simons M 2000 Deformation and seismicity in the Coso geothermal area, Inyo County, California:
Observations and modeling using satellite radar interferometry. Journal of Geophysical Research, 105, 21, 781-21, 794

[5] Floyd MA and Funning GJ Continuation of survey GPS measurements and installation of continuous GPS sites at The Geysers, California, for geothermal deformation monitoring. California: University of California

[6] Ge L, Rizos C, Han S and Zebker H 2001 Mining subsidence monitoring using the combined insar and gps approach. The 10th FIG International Symposium on Deformation Measurements. Orange, Carlifornia USA

[7] Heimlich C, Masson F and Gourmelen N 2013 Geodetic monitoring at the geothermal sites of Soultz-sous-Forêts and Rittershoffen (Upper Rhine Graben - France). European Geothermal Congress . Pisa, Italy

[8] Massonnet D, Holzer T and Vadon H 1998 Land subsidence caused by the East Mesa gethermal field, California, observed using SAR interferometry. Geophysical Research Letters , p. 25

[9] Sousa J J, Ruiz A M, Hanssen R F, Bastos L, Gi A J, J G-Z et al. 2010. PS-InSAR processing methodologies in the detection of field surface deformation - Study of the Granada basin (Central Betic Cordilleras,Spain. Journal of Geodynamics , 181-189 